\title{
MEMORIJSKE DISTORZIJE U ISTRAŽIVANJU EMOCIJA ${ }^{1}$
}

Apstrakt: Psihologe su odvajkada intrigirali razni aspketi funkcionisanja ljudskog pamćenja. Kapacitet memorije prosečnog odraslog čoveka, razni viši kognitivni procesi koji su krucijalni za kodiranje, skladištenje i organizaciju sećanja, kao i fenomen zaboravljanja - samo su neke od tema koje su naučnici intenzivno izučavali u okviru raznih subdisciplina psihologije. U ovom preglednom članku prvo je dat detaljan prikaz najpoznatijih rezultata empirijskih istraživanja koja su se bavila tačnošću sećanja na emocionalno obojene događaje iz prošlosti. Opisane su do sada otkrivene pravilnosti u javljanju tzv. memorijskih distorzija u sećanjima na osećanja izazvana prošlim intenzivnim i značajnim iskustvima. U drugom delu rada fenomen memorijskih iskrivljenja smešten je u širi konceptualni okvir stres-procesa i predstavljena su empirijska istraživanja koja su imala za cilj utvrđivanje stepena tačnosti sećanja na suočavanje sa raznim stresnim transakcijama koje su se odvijale u prošlosti. Takođe, prodiskutovana je uloga osobine neuroticizma u nastanku memorijskih distorzija.

Ključne reči: memorijske distorzije, emocije, suočavanje sa stresom, neuroticizam.

„Neki događaji su toliko emocionalno obojeni, da ostavljaju ožiljak na cerebralnom tkivu.“ (James, 1890, prema Kensinger, 2009: 99). Deceniju stare reči Vilijama Džejmsa (William James) verno odslikavaju oduvek postojeću ljudsku ideju: iako naša sećanja nisu uvek u potpunosti tačna, ponekad iznenađujuće precizno čuvaju određene životne trenutke. Čovekova memorija je paradoksalna tvorevina - istovremeno je izdržljiva i često neumoljivo čvrsta, a u drugim slučajevima prilično krhka i podložna promenama i iskrivljenjima. Svi posedujemo trajne memorijske tragove na neke, najčešće za nas bitne događaje, kao što je npr. dan našeg venčanja ili trenutak spoznaje da smo izgubili voljenu osobu, a ne možemo da se setimo sitnica koje su se odigrale pre svega nekoliko minuta. Čak i kada zapamtimo neko iskustvo iz prošlosti, garancije da su naša sećanja potpuno verne reprodukcije originalnog događaja ne postoje. Takođe, neretko imamo vrlo jasnu sliku nekih aspekata zapamćene situacije, dok određeni detalji istog događaja ostaju u mutnoj senci. Međutim, čak i ona sećanja za koje smo udeđeni da su detaljna i precizna, vrlo verovatno su u velikoj meri pod preoblikujućim dejstvom

Ana Genc, annag@neobee.net 
naših aktuelnih razmišljanja i osećanja, osobina ličnosti i iskustava koje smo imali u periodu između doživljenog i trenutka prisećanja. Iako najčešće nismo uvek svesni grešaka koje naš mozak pravi tokom pokušaja reprodukcije prošlosti, čak ni laici nisu iznenađeni kada saznaju da ljudska memorija nije savršena. Uzmimo za primer bračni par koji se sporečkao upravo zbog različitih sećanja na isti događaj ili iritirajući utisak da nam je osoba koju srećemo na ulici odnekud jako poznata, ali nikako ne možemo da se setimo kada i gde smo je već videli.

\section{SEĆANJA NA DOGAĐAJE IZ PROŠLOSTI}

Sećanja na određene događaje iz života nazivaju se još i autobiografskim sećanjima i predstavljaju dinamične mentalne konstrukcije (Bartlett, 1932, prema Safer, Bonnano, \& Field, 2001). Saznanje da su emocionalno neutralna sećanja u velikoj meri podložna promenama i nisu verna kopija originalnog materijala, opšte je prihvaćeno u psihologiji još od vremena prvih Bartletovih eksperimenata $u$ području memorije. Ideje o sadržajima koje smo iskusili u prošlosti nikako nisu puke reprodukcije. One predstavljaju pre rekonstrukcije zasnovane na informacijama o izvornom događaju koje smo prikupili nakon prvog susreta sa materijalom koji smo usvajali i u velikoj meri zavise od naših kasnijih kognitivnih procena i osećanja (Loftus, 1992, prema Levine, \& Pizarro, 2004). Dugo je vladalo uverenje da je situacija sa događajima obojenim (snažnim) emocijama drugačija i da takva iskustva ostavljaju trajne, čak neizbrisive tragove u memoriji. U članku koji se danas već smatra klasikom u domenu psihologije, Braun i Kjulik (Brown, \& Kulik, 1977, prema Kensinger, 2009) izložili su teoriju o tzv. blic sećanjima (flashbulb memories, engl.) ili, kako se još nazivaju: emocionalnim sećanjima. Prema njihovom shvatanju, u ljudskom mozgu postoji određeni mehanizam zadužen za zapamćivanje onih životnih iskustava koja su biološki izuzetno važna, a istovremeno su nova i neočekivana. Autori tvrde da su blic sećanja, upravo zbog njihovog velikog značaja za preživljavanje, najčešće zapamćena sa gotovo fotografskom preciznošću. U njihovom istraživanju, Braun i Kjulik su od ispitanika tražili da opišu okolnosti neke situacije u kojoj su prvi put čuli za odigravanje određenog, emocionalno snažno obojenog događaja, kao što je, na primer, ubistvo američkog predsednika Kenedija (Kennedy). Izveštaji subjekata su bili iznenađujuće detaljni, sa brojnim podacima o tome gde su se tačno nalazili u vreme saznavanja šokantnih vesti, šta se dešavalo u tom trenutku, ko im je saopštio novosti i kako su se tada osećali. U suprotnosti sa sećanjima na neutralna, svakodnevna iskustva, emocionalna sećanja su sadržavala živopisne, idiosinkretične detalje, koji su pokazivali izraženu tendenciju trajanja.

Tvrdnje o neizbrisivosti blic sećanja inspirisale su veliki broj istraživanja koja su se bavila pitanjem u kojoj meri su ta sećanja zaista tačna i precizna. Mnogi naučnici su uspeli da demonstriraju da živopisnost i bogatstvo detaljima, koji su toliko karakteristični za emocionalna sećanja, nikako ne podrazumevaju i njihovu tačnost. Tako su, na primer, Najser i Harš (Neisser, \& Harsch, 1992, prema 
Kensinger, 2009) ukazali na postojanje memorijskih distorzija kod studenata od kojih su tražili da se prisete okolnosti u kojima su saznali za eksploziju spejs šatla „Challenger". Iako je, na primer, jedan ispitanik u prvom vremenu merenja sa potpunom sigurnošću tvrdio da je za vest čuo od prijatelja, kada su subjekti nakon šest meseci ponovo upitani za okolnosti u kojima su saznali za tragediju, ista ta osoba je vrlo samouvereno izjavila da je za događaj prvi put čula na televiziji. U jednoj savremenijoj studiji Talariko i Rubin (Talarico, \& Rubin, 2003, prema Levine, \& Pizarro, 2004) upoređivali su sećanja ispitanika na situaciju kada su prvi put čuli za terorističke napade koji su se odigrali 11. septembra 2001. godine u Sjedinjenim Državama, sa sećanjima na nedavne svakodnevne događaje. Prema njihovim rezultatima, oni subjekti koji su izveštavali o intenzivnijim emocionalnim reakcijama, ujedno su i više bili ubeđeni u tačnost svojih sećanja, međutim, jaka osećanja nisu garantovala i konzistentnost memorije. U suprotnosti sa ovim istraživanjem, drugi naučnici su dobili rezulate, prema kojima jače emocije jesu povezane sa većom konzistentnošću memorije tokom vremena. Kao primer mogu da se navedu Konvejeva (Conway et al., 1994, prema Levine, \& Pizarro, 2004) ispitivanja sećanja na davanje ostavke britanske premijerke Margaret Tačer (Maragaret Thacher). Građani Velike Britanije koji su izveštavali o jačim osećanjima izazvanim tim događajem, ujedno su bili više konzistentni u svojim sećanjima tokom dužeg vremenskog perioda. Uprkos navedenim razlikama, svi naučnici koji su se bavili izučavanjem sećanja na emocijama obojene događaje slažu se oko jedne bitne karakteristike ljudske memorije: ona je u velikoj meri podložna raznim distorzijama i sadrži priličan broj grešaka. Na osnovu do sada prikupljenih empirijskih podataka, sa velikom sigurnošću možemo da tvrdimo, da najbolje pamtimo suštinu prošlih iskustava i implikacije koje su ti događaji imali za nas lično.

Pregledom literature iz domena memorije i emocija uočava se jedna posebna linija istraživanja: ispitivanja kako prijatnost, odnosno neprijatnost određenog životnog iskustva utiče na njegovo zapamćivanje. Emocije vremenom postaju bleđe. Većina ljudi je barem jednom tokom života bila izložena nekom izuzetno neprijatnom stresoru, kao što su npr. smrt voljene osobe ili prekid važnog međuljudskog odnosa. Osećanja prouzrokovana ovakvim događajima su najčešće intenzivna, bolna i dugotrajna. Međutim, kako meseci i godine prolaze, neprijatnost povezana sa sećanjem na to iskustvo postepeno gubi snagu. Situacija sa sećanjem na prijatne životne događaje nije mnogo drugačija - sreća, zadovoljstvo, ponos i druga pozitivno obojena osećanja takođe pokazuju tendenciju slabljenja. Rezultati do sada sprovedenih empirijskih istraživanja su u velikoj meri međusobno slični: većina naučnika smatra da se ljudi generalno lakše i detaljnije sećaju prijatnih ličnih iskustava. Ipak, iako u manjem broju, moguće je pronaći i suprotne nalaze, koji predstavljaju izuzetak navedenoj opštoj pravilnosti. Voker (Walker) je mišljenja da su kontradiktorni rezultati posledica razlika u intenzitetu emocija koje su doživljene za vreme zapamćivanja konkretnog događaja i jačine osećanja u trenutku kada se vrši prisećanje na taj materijal. Njegov argument baziran je na 
razlikama u slabljenju različitih osećanja tokom vremena, koje je prvi put uočio još Kejson, 1932. godine (Cason, 1932, prema Walker, Vogl, \& Thompson, 1997).

Kejson je od ispitanika tražio da opišu nekoliko, za njih važnih događaja iz prethodne sedmice, a zatim da za svaki navedu korespondirajuća osećanja koja se u njima aktiviraju dok razmišljaju o konkretnom dešavanju. Nakon tri nedelje, subjekti su ponovo procenjivali emocionalne reakcije na iste događaje. Autor je na bazi prikupljenih podataka uočio jasnu sklonost ka slabljenju osećanja tokom vremena. Ova tendencija je bila više izražena u slučaju neprijatnih događaja. Inspirisan Kejsonovim eksperimentom, nekoliko decenija kasnije Holms (Holmes, 1970, prema Walker, Skowronski, Gibbons, \& Vogl, 2003) je pokušao da replicira njegove rezultate i da temeljnije objasni fenomen boljeg zapamćivanja pozitivnih životnih iskustava, u poređenju s negativnim. Zadatak Holmsovih ispitanika podrazumevao je beleženje kako prijatnih, tako i neprijatnih svakodnevnih događaja, kao i navođenje za njih vezanih osećanja. Identifikovanje emocionalnih reakcija na ista dešavanja ponovljeno je nedelju dana kasnije. Osnovni nalazi ove studije identični su Kejsonovim rezultatima: jačina emocija izazvanih negativnim događajima brže i više opada. Takođe, subjekti su se lakše prisećali detalja vezanih za prijatna iskustva. Holms je zaključio, kako je opšta ljudska sklonost da se poželjni, pozitivni događaji bolje pamte, posledica sporijeg slabljenja i zaboravljanja prijatnih afektivnih reakcija.

Zahvaljujući savremenim istraživanjima, naučnici su još više precizirali zaključke o razlikama između zapamćivanja pozitivnih i sećanja na negativno konotirane događaje. Na osnovu do sada prikupljenih nalaza sa relativno velikom sigurnošću možemo da tvrdimo sledeće: ljudi se generalno lakše prisete prijatnih iskustava koja su u njima izazvala pozitivna osećanja, međutim, ta lakoća u „memorijskom prizivanju“ uopšte ne podrazumeva nužno i preciznost sećanja. Čini se da su sećanja na nelagodna dešavanja tačnija i manje pod dejstvom memorisjkih iskrivljenja i grešaka (Levine, \& Bluck, 2004). Prema jednom od mogućih tumačenja, za pozitivna osećanja su vezane drugačije strategije procesiranja informacija, nego što je to slučaj sa neprijatnim emocijama. Ljudi su srećni i zadovoljni kada uspešno postignu željene ciljeve i kada trenutno nisu suočeni s nekim gorućim problemom kojeg treba da reše. U tim okolnostima, tačnije u uslovima koji nisu stresne prirode, pojedinac ne ulaže dodatni kognitivni napor pri pokušajima rekonstrukcije detalja vezanih za prošli, benigni događaj i trudi se da sačuva aktuelno prijatno emocionalno stanje i subjektivni doživljaj dobrobiti. Kada je dostizanje zacrtanih ciljeva ugroženo, aktiviraju se neprijatna osećanja i stres-proces. Osobe u negativnom emocionalnom stanju su mnogo pažljivije tokom kognitivne obrade informacija, sistematičnije su i manje se oslanjaju na „opšta znanja“ o tome šta je moglo da se desi, one pokušavaju da prizovu zaista tačne detalje o prethodnom, pretećem ili na bilo koji drugi način nepoželjnom događaju.

Brojni laboratorijski eksperimenti iz oblasti socijalne psihologije potvrđuju gore opisano rezonovanje. Ako ispitanicima na veštački način indukujemo 
pozitivna, odnosno negativna osećanja, razlike u njihovom misaonom funkcionisanju postaju uočljive. Utvrđeno je, na primer, da osećanje sreće podstiče kreativnost, fleksibilnost i druge divergentne kognitivne procese, dok osobe koje su uplašene ili tužne u svojim razmišljanjima su mnogo rigidnije, pokazuju sklonost da se oslanjaju prevashodno na činjenične podatke i donose konzervativne sudove. Posebno je zanimljivo istraživanje Blesa i saradnika (Bless et al., 1996, prema Live, \& Bluck, 2004). Autori su kod subjekata prvo izazvali ili prijatna ili negativna osećanja, a zatim su im prezentovali informacije o uobičajenim, svakodnevnim aktivnostima, poput ručavanja u restoranu. Neke od informacija su bile logične i očekivane (npr.: „Konobarica je stavila jelovnike na sto.“), dok su druge bile atipične i neočekivane (npr.: „Konobarica je odložila svoj reket za tenis."). U drugom delu eksperimenta, ispitanicima je zadat test prepoznavanja, koji je sadržao, kako prethodno prikazane, tako i nove informacije. Utvrđeno je da su srećni subjekti češće ,,prepoznavali“ tipične podatke, bez obzira na to da li su oni zaista bili prezentovani u prvom delu istraživanja. Tužni ispitanici su bili tačniji i precizniji u svojim sećanjima. Prema tome, prijatno emocionalno stanje češće ima za posledicu oslanjanje na opšta znanja i stereotipe.

\section{SEĆANJA NA EMOCIJE IZ PROŠLOSTI}

Pored tačnosti sećanja na činjenice o dešavanjima iz prošlosti, psihologe zanima i koliko tačno pamtimo naša osećanja koja smo doživljavali za vreme trajanja određenog događaja. Jedno od prvih istraživanja na ovu temu sprovela je autorka Linda Levajn (Levine, 1997). 16. jula 1992. godine političar Ros Perot (Ross Perot) objavio je da povlači svoju kandidaturu za Američkog predsednika. Vest je šokirala njegove sledbenike, od kojih su mnogi izveštavali o emocionalnim reakcijama očaja i ljutnje na ovaj iznenadni razvoj događaja. Nedugo nakon Perotovog povlačenja Levajnova je prikupila uzorak ispitanika sačinjenih od pristalica dotičnog političara i zamolila ih da se prisete koliko su intenzivno iskusili osećanja tuge, besa i nade kada su saznali za Perotovu odluku. Subjekti istraživanja su takođe imali zadatak da opišu svoje interpretacije i kognitivne procene vezane za aktuelna dešavanja. Nakon što su ga medije osramotile nazivajući ga kukavicom i zabušantom, Perot je u oktobru iste godine odlučio da obnovi svoju kandidaturu $i$ iako na izborima nije pobedio, petina građana Sjedinjenih Država glasala je za njega. Levajnova je odlučila da iskoristi ovaj neočekivani obrt koji je pružio izuzetno retku priliku za naturalistički eksperiment s zadatkom izučavanja sećanja na emocije iz prošlosti. Cilj njenog istraživanja bio je dvostruk: a) ispitivala je vremensku stabilnost sećanja na osećanja i b) zanimao ju je uticaj kognitivnih procena na distorzije u memoriji. Autorka je grupisala ispitanike na osnovu promena koje su se tokom vremena odigrale u njihovim kognitivnim procenama. Relacije između inicijalnih izvešataja o osećanjima besa, tuge i nade i kasnijih prisećanja na ove emocije su posebno izučavane u svakoj grupi subjekata. Rezultati istraživanja su otkrili da su sećanja Perotovih pristalica na prošle emocionalne 
reakcije bila u velikoj meri pogrešna i pod statistički značajnim uticajem njihovih kasnijih kognitivnih procena. Tako su, na primer, oni subjekti koji su favorizovali Perota nakon njegove obnovljene kandidature potcenili jačinu sopstvenih osećanja besa i tuge iz vremena političareve objave povlačenja. Istim ovim ispitanicima se činilo da su osećali intenzivniji stepen nade, nego što je ta emocija zaista bila prisutna kod njih u prvom vremenu merenja. Za razliku od ove grupe subjekata, oni pojedinci koji su se u međuvremenu okrenuli protiv Perota, imali su tačna sećanja na jačinu sopstvenog besa, ali su potcenili stepen nade koju su na početku eksperimenta osećali.

U literaturi nailazimo na prilično ograničen broj onih istraživanja koja su se bavila specifičnim pitanjem: „Da li su ljudi generalno skloniji da precene ili da potcene intenzitet svojih emocionalnih reakcija na važne prošle događaje?“. Većina dosadašnjih rezultata je slična: kada se prisećamo na manje ili više davno doživljena afektivna stanja, najčešće nam se čini da su naša osećanja bila jača, nego što je to zaista bio slučaj u trenutku proživljavanja tih emocija. Tako se, na primer, pokazalo da su depresivni pacijenti precenjivali intenzitet njihovih ranijih faza disforije (Schrader et al., 1990, prema Keuler, \& Safer, 1998), klijentima se, nakon završavanja terapijskog procesa činilo da je stepen njihovog distresa pre započinjanja savetovanja bio jači, nego što je uistinu registrovano (Safer \& Keuler, 2002), pacijenti koji su prolazili kroz izuzetno bolnu medicinsku proceduru, naknadno su precenili jačinu sopstvene anksioznosti i depresije od pre početka tretmana (Linton, 1991, prema Breckler, 1994) i davaoci krvi su bili ubeđeni da su osećali veći stepen strepnje pre donacije krvi, u poređenju s nivoom anksioznosti o kojem su tada zaista izveštavali (Breckler, 1994). Autori navedenih korelacionih istraživanja slažu se u tumačenju dobijenih sličnih nalaza: ispitanici su skloni preuveličavanju sopstvenog uspeha u suočavanju sa nekom pretećom, opasnom situacijom, a to čine kroz precenjivanje svojih inicijalnih negativnih emocija. Kao da razmišljaju na sledeći način: „Dešavale su mi se užasne stvari, osećao sam se jako loše, a uprkos tome sam uspeo da se izborim s neprilikama." Čini se da ovakav ili sličan način rezonovanja sadrži impilictinu i verovatno nesvesnu želju osobe da zadrži ili izgradi pozitivnu samopercepciju, ocenjujući sebe kao snažnog, snalažljivog, veštog i sl. Međutim, nikako ne smemo izgubiti iz vida važnost uticaja kasnijih kognitivnih procena na sećanje (Levine et al., 2001), jer u pojedinim slučajevima određene misli mogu da rezultiraju pre u potcenjivanju intenziteta prošlih osećanja, a ne u njihovom preuveličavanju.

O uticaju kognitivnih procena na tačnost sećanja na prošle emocije svedoče i nalazi još jedne bitne studije Levajnove i saradnika. U ovom istraživanju iz 2001. godine, autori su tražili od subjekata da se prisete sopstvenih afektivnih reakcija na vest da je O. J. Simpson oslobođen optužbi za ubistvo supruge. Izveštaji o sećanjima na osećanja prikupljeni su nedelju dana, dva meseca i 14 meseci nakon objave presude. U svakom vremenu merenja ispitanici su imali zadatak da opišu i njihove trenutne kognitivne procene vezane za Simpsona i ceo događaj. Rezultati su svedočili o tome da su sećanja na primarne emocionalne reakcije besa ili sreće 
bila manje vremenski stabilna, ukoliko su se u međuvremenu promenile kognitivne procene subjekata istraživanja. Takođe, na osnovu aktuelnih misli i stavova bilo je moguće predvideti smer memorijskih distorzija: oni ispitanici koji su u trenutku, na primer, drugog vremena merenja smatrali da je O. J. Simpson kriv, pokazivali su jasnu sklonost ka kasnijem precenjivanju sopstvenog besa, a istovremeno su naknadno potcenili osećanje sreće u poređenju sa inicijalnim izjavama (Levine et al., 2001, prema Levine, \& Safer, 2002).

Još jedno zanimljivo istraživanje preciznosti sećanja na prošle emocije sproveli su Holmberg i Holms (Holmberg, \& Holmes, 1994, prema Levine, \& Pizarro, 2004). Oni su dokazali da su muževi čiji su brakovi vremenom postali manje zadovoljavajući u svojim sećanjima izveštavali o negativnijim interakcijama $\mathrm{s}$ početka braka, nego što je to zaista bio slučaj. Takođe, pokazalo se da su se sećanja o stepenu distresa koji su ljudi doživljavali u trenutku saznavanja za terorističke napade na SAD 2001. godine menjala kako je vreme prolazilo. Promene su zavisile od toga kako je konkretna osoba u drugom vremenu merenje procenjivala naknadni uticaj ovog nemilog događaja (Levine, Whalen, Henker, \& Jamner, 2005).

Pored uticaja kognitivnih procena na tačnost ljudske memorije, pojedine istraživače je zanimalo kako aktuelna afektivna stanja deluju na procese reprodukcije događaja i emocija iz prošlosti. Oni su pretpostavili da su sećanja na prošla osećanja pod dejstvom trenutnih, ,svežih“ emocija. Ova hipoteza uspešno je potvrđena (između ostalog) u istraživanju Sejfera i saradnika (Safer, Bonanno, \& Field, 2001). U njihovoj longitudinalnoj studiji autori su od grupe udovica $i$ udovaca tražili da ocene intenzitet sopstvenog osećanja tuge prvo šest meseci posle gubitka životnog saputnika, a zatim su isti postupak ponovili pet godina nakon smrtnog slučaja. Kada su u drugom vremenu merenja ispitanici zamoljeni da se sete jačine tuge iz prvog vremena merenja, njihov izveštaj je bio više u skladu sa trenutnim intenzitetom ovog osećanja, nego sa izjavama koje su davali na početku istraživanja. Prema tome, sećanja na emocije iz prošlosti su pod značajnim uticajem trenutnog afektivnog stanja.

Krajnji zaključak svih navedenih istraživanja podrazumeva da su sećanja na emocionalne reakcije iz prošlosti barem delimično rekonstruisana na bazi trenutnih kognitivnih procena tih prethodnih događaja i osećanja koja su prisutna u trenutku prisećanja. Međutim, s obzirom da je reč o studijama korelacione prirode, nikako ne možemo sa stopostotnom sigurnošću da tvrdimo da su distorzije u sećanjima na prošle emocije prouzrokovane promenama u subjektivnim procenama. Isti rezultati mogu da se interpretiraju i dijametralno suprotno: možda su memorijska iskrivljenja ta koja proizvode promene u kognitivnim procenama. Kako bi utvrdili „šta je bilo pre, kokoška ili jaje“ Kojler i Sejfer (Keuler, \& Safer, 1998) su sproveli za ovaj domen nauke vrlo relevantan eksperiment. Autori su procenili stepen izraženosti ispitne anksioznosti kod grupe studenata pre polaganja važnog ispita. Nakon toga, ispitanici su podeljeni u dve grupe po principu slučajnosti. Subjektima iz prve grupe su saopštene njihove ocene, pre nego što su u drugom vremenu merenja trebali da se prisete sopstvenog emocionalnog stanja koje je bilo prisutno 
pre evaluativne situacije. Tokom testiranja sećanja na osećanja druga grupa studenata nije bila upoznata sa rezultatima koje su na ispitu postigli. Oni su ove informacije dobili tek nakon završetka eksperimenta. Rezultati su ukazali na zanimljivu pravilnost: one osobe koje su tokom drugog vremena merenja već znale da su bile uspešne na ispitu, pokazale su jasnu tendenciju precenjivanja sopstvene ispitne anksioznosti pre ispitne situacije. U suprotnosti s njima, ispitanici koji su saznali da nisu položili ispit, kasnije su izveštavali o nižem stepenu evaluativne strepnje, nego što je registrovano pre polaganja. Prema tome, informacije koje su dobijene nakon polaganja ispita prouzrokovale su distorzije u sećanjima na osećanje ispitne anksioznosti koje je postojalo neposredno pre evaluativne situacije.

Summa summarum, do sada prikupljeni empirijski nalazi govore u prilog tome, da kako sećanja na događaje koji izazivaju snažne emocionalne reakcije, tako ni sećanja na konkretna osećanja tokom tih dešavanja, nikako ne predstavljaju trajne i apsolutno tačne reprodukcije originalnih iskustava. Kao i u slučaju sećanja na svakodnevne „neemocionalne“ događaje, blic sećanja su takođe podložna promenama tokom vremena i pod dejstvom su informacija koje smo naknadno prikupili o tom događaju, stavova, aktuelnih kognitivnih procena i trenutnog emocionalnog stanja osobe (Levine, \& Safer, 2002). Međutim, uprkos opisanim iskrivljenjima, i dalje se čini da ljudi generalno bolje pamte nove, neočekivane događaje koji kod njih izazivaju određena osećanja, u poređenju sa neutralnim dešavanjima kojima se ne pripisuje neka posebna važnost. Kada se napravi neka vrsta opšteg preseka do sada nagomilanih empirijskih nalaza, možemo da zaključimo da se između intenziteta osećanja kojih se subjekti naknadno prisećaju i jačine emocije koja je inicijalno bila zabeležena postoji pozitivna korelacija koja najčešće iznosi oko .50 (ili u nekim slučajevima čak više) (Safer, Bonnano, \& Field, 2001; Levine, \& Safer, 2002; Safer, Breslin, Boesch, \& Cerqueira, 2007).

Istraživanje sećanja na osećanja iz prošlosti svakako imaju veliki, kako praktični, tako i teorijski značaj. Iz aspekta prakse, dijagnostičke odluke i planovi psiholoških tretmana mnogih psihopatoloških poremećaja i kriznih, odnosno traumatskih stanja, baziraju se upravo na subjektivnim izveštajima klijenata o njihovim prošlim emocionalnim reakcijama. Bezbroj kliničkih instrumenata ima za cilj registrovanje afektivno obojenih iskustava iz određenog perioda pacijentovog života. Takođe, u nekliničkim uslovima sećanja na prošle emocije umnogome utiču na razne aspekte ljudskog funkcionisanja (Levine, 1997). Na kraju krajeva, sasvim je moguće da je primarna funkcija ljudske memorije usmeravanje budućih ponašanja, a ne samo puko čuvanje informacija iz prošlosti. Prisećanja na prošla osećanja prijatnosti, odnosno neprijatnosti dozvoljavaju nam da tragamo za situacijama s kojima smo već imali pozitivna iskustva, a istovremeno da izbegavamo one okolnosti za koje se pokazalo da nam ne prijaju ili čak da nam štete. 


\section{SEĆANJA NA SUOČAVANJE SA STRESOM IZ PROŠLOSTI}

Domenima mentalnog zdravlja i psihologije ličnosti su u proteklih nekoliko decenija u velikoj meri dominirala istraživanja stresa i suočavanja s njim. Rođenje i razvoj skala za registrovanje velikih životnih događaja (npr. Holmes \& Rahe, 1967) omogućilo je izučavanje relacija koje postoje između stresora i raznih psihosocijalnih ishoda, s akcentom na mehanizme suočavanja koji predstavljaju značajne medijatore u odnosu između stresnih stimulusa i posledica stresnih transakcija. 70-ih godina prošlog veka počeo je rapidan razvoj brojnih upitnika za procenu individualnih razlika u suočavanju (Folkman, \& Lazarus, 1985; Endler, 1997). Uprkos tome što se ovi merni instrumenti međusobno razlikuju po tome koje strategije i postupke suočavanja registruju, primetna je jako velika sličnost u opštem pristupu i načinu merenja: od subjekata istraživanja se, po pravilu, traži da opišu neki stresni događaj koji su doživeli u proteklom periodu (npr. tokom prethodne sedmice ili meseca i sl.) i da identifikuju konkretne misli i ponašanja na koje su se oslanjali u pokušajima prevladavanja neprijatnosti. Upravo opisani pristup psihološkog merenja poseduje dve krucijalne karakteristike: oslanjanje na subjektivne izjave ispitanika i retrospektivnost, pri čemu se prisećanje na primenjene postupke suočavanja neretko vrši nedeljama ili čak mesecima nakon njihove stvarne primene. Pregledom stotine naučnih članaka o suočavanju sa stresom koji se nalaze u bazama poput PsycLIT i MEDLINE jasno se uočava da se velika većina autora u svojim istraživanjima oslanjala ili na dispozicione definicije suočavanja („Kako se uobičajeno, najčešće suočavate sa stresom?“”) ili na retrospektivne izveštaje ispitanika o (ponekad davno) prošlim događajima i njihovim reakcijama na te okolnosti (Smith, Leffingwell, \& Ptacek, 1999).

Istraživači su odavno svesni upitne validnosti upotrebe samo-opisnih metoda u proceni psiholoških varijabli i kontroverze vezane za (ne)opravdanost oslanjanja na rezultate dobijene, na primer, upitnicima su i dalje vrlo aktuelne u savremenoj literaturi. Pretnje po valjanost, između ostalog, uključuju sklonost ljudi da se tokom odgovaranja na ajteme iz skala koriste raznim nesvesnim odbrambenim mehanizmima koji vode ka neiskrenim, neistinitim izjavama, nepostojanje garancije da svi ispitanici tumače stavke mernih instrumenata na identičan način, tendencija pojedinih subjekata istraživanja da daju socijalno poželjne odgovore ili da ekstremno odgovaraju itd. Ipak, uprkos navedenim problemima, tehnike prikupljanja empirijskih podataka koje se oslanjaju na samo-iskaze ispitanika često ostaju jedini mogući način za registrovanje prikrivenih, intrapsihičkih fenomena. S obzirom da suočavanje sa bilo kakvom vrstom stresora podrazumeva određene misli koje se, naravno, golim okom ne mogu videti i kojima jedino ispitanici ,imaju pristup“ ili ponašanja koja su se odigravala u prošlosti, naučnici nemaju izbora - moraju da se oslanjaju na izjave subjekata istraživanja (Ptacek, Smith, Espe, \& Raffety, 1994).

Druga inherentna osobina istraživanja suočavanja sa stresom je retrospektivno prisećanje na pokušaje prevladavanja iz prošlosti, a ovoj karakteristici je posvećeno 
daleko manje empirijske pažnje. Osnovna premisa na koju se sva retrospektivna istraživanja suočavanja sa stresom a priori oslanjaju podrazumeva ,aksiom“ da su ljudi sposobni na tačno i precizno sećanje na ponašanja iz prošlosti. Međutim, sada smo već uvereni u netačnost ove polazne pretpostavke: ljudi nisu u stanju da verodostojno, bez distorzija izveštavaju o mislima, osećanjima i postupcima koje su koristili tokom prethodnih pokušaja suočavanja sa stresom (Stone et al., 1998). A ako su podaci koje prikupljamo od ispitanika nedovoljno pouzdane refleksije stvarnih prevladavajućih akcija, postavlja se izuzetno neprijatno pitanje: „Da li su do sada ustanovljene relacije između suočavanja i drugih varijabli stres-procesa uopšte validne i relijabilne, ako sam način merenja suočavanja dovodi do pogrešnih zaključaka?". S obzirom na težinu i ozbiljnost posledica iskrenog i tačnog odgovora na navedeno pitanje, nije iznenađujuća tendencija ignorisanja ovih nedoumica od strane velike većine naučnika.

Netačnost retrospektivnih izveštaja od strane subjekata istraživanja može da rezultira iz nekoliko različitih faktora. Proticanje vremena, samo po sebi, odnosno druge aktivnosti koje vršimo dok vreme prolazi, mogu da dovedu do iskrivljenja u memoriji kroz procese retroaktivne inhibicije (Ebbinghaus, 1885/1964, prema Ptacek et al., 1994). Sklonost pojedinih ispitanika da svesno ili nesvesno sebe predstave u određenom, najčešće pozitivnije obojenom svetlu, takođe ima za posledicu dobijanje nepouzdanih podataka (Todd, Tennen, Carney, Armeli, \& Affleck, 2004). Zatim, utvrđeno je da se ljudi, tokom prisećanja na sopstvena ponašanja iz prošlosti, često oslanjaju na uverenja o tome kako oni najčešće, uobičajeno, tipično postupaju. Prema tome, izveštaji o suočavanju iz prošlosti mogu da predstavljaju opšte ubeđenje konkretne osobe o svojim bihejvioralnim tendencijama i šablonima, odnosno generalizovano ,znanje“ o sebi, a ne stvarno postojeći memorijski trag o zaista izvedenim akcijama u datoj prošloj stresnoj transakciji (Stone et al., 1998). Još jedan razlog za pojavu distorzija u sećanjima na prošlo suočavanje može da se krije u pogrešnom enkodiranju konkretnog događaja iz prošlosti (Smith, Leffingwell, \& Ptacek, 1999). Greške u samom procesu skladištenja sećanja su posebno česte i predstavljaju krajnje uobičajenu pojavu u slučaju izloženosti traumatskim događajima. Kada se pojedinac susretne sa izuzetno teškim, neočekivanim, ugrožavajućim događajima koji su izvan uobičajenog ljudskog iskustva (npr. saobraćajna nesreća, silovanje, zemljotres itd.), sećanja na strahote su, zbog mehanizama kao što su disocijacija ili potiskivanje, pogrešno ugrađena u već postojeće memorijske mreže, a samim tim su i izveštaji osobe o reakcijama na događaj pod uticajima memorijskih distorzija (Eloffson, Scheele, Theorell, \& Söndergaard, 2008). Prisećanje na prošlo suočavanje može da bude iskrivljeno zbog uticaja znanja o tome kako se data stresna situacija okončala. Moguće je pronaći zadovoljavajuće empirijske podatke koji potkrepljuju ideju, da ljudi sistematski iskrivljuju svoja sećanja kako bi održali nerealistično pozitivnu sliku o sebi. Na primer, ako se određena stresna transakcija završi sa pozitivnim ishodima, pojedinac će vrlo rado i često smatrati da je zadovoljavajući rezultat posledica njegovog veštog, zdravog, adaptivnog, pametnog i sl. postupanja 
i selektivno će se sećati samo adekvatnih, na problem usmerenih strategija suočavanja (Ptacek et al., 1994).

Kao jedno od mogućih objašnjenja pojave iskrivljenih sećanja na suočavanje iz prošlosti posebno se ističe Rosov model o implicitnim teorijama stabilnosti i promene (Ross, 1989, prema Todd et al., 2004). Čini se, da su ljudi generalno skloni tome da rekonstruišu svoja prethodna iskustva kroz organizaciju dostupnih memorijskih fragmenata, u skladu sa sopstvenom implicitnom teorijom o tome šta se najverovatnije desilo u konkretnoj prošloj situaciji. Prema tome, autor smatra da kada su ispitanici zamoljeni da izveste o svojim suočavajućim postupcima koje su koristili u određenoj stresnoj transakciji, oni će odgovarati u skladu sa njihovom implicitnom teorijom o promeni. Rosove ideje su u velikoj meri potvrđene i rezultatima istraživanja koje su sproveli Hamilton i Fagot (Hamilton, \& Fagot, 1988, prema Todd et al., 2004). Prema njihovim nalazima, žene su češće izveštavale o korišćenju suočavajućih postupaka koje su usmerene na emocije, dok su se muškarci navodno više oslanjali na mehanizme prevladavanja koji su usmereni na problem. Međutim, kada su autori sproveli drugo istraživanje, u kojem su od subjekata tražili da tri puta sedmično, tokom osam nedelja beleže stresore s kojima su se susretali i suočavajuće postupke na koje su se oslanjali, nisu dobijene statistički značajne razlike u suočavanju između muškaraca i žena. Autori su ove nalaze objasnili sklonošću ispitanika da odgovaraju na upitnike u skladu sa svojim implicitnim teorijama o tome kako se muškarci ponašaju u stresnim situacijama, odnosno šta žene rade kada su pod uticajem distresa. Dakle, mnogi odgovori na psihološke upitnike mogu da budu pod značajnim dejstvom stereotipa i predrasuda koje imamo o sebi ili grupama kojima pripadamo.

Kako bi se „,vremenski približili“" korišćenim suočavajućim postupcima, pojedini istraživači su se opredelili za procedure prikupljanja podataka koje podrazumevaju svakodnevne izveštaje ispitanika o tome kako su se ponašali u određenim stresnim transakcijama koje su se odigravale tokom tog dana. Ovakva vrsta „dnevničkog ispitivanja“, iako se i dalje oslanja na subjektivne samo-iskaze subjekata istraživanja, značajno skraćuje vreme između korišćenih strategija suočavanja i izveštavanja o njima, pa samim tim se smanjuje verovatnoća pojave uticaja temporalnih faktora na prisećanje (Smith, Leffingwell, \& Ptacek, 1999). Nekoliko savremenih studija su imale za cilj da uporede rezultate o suočavanju sa stresom koji su bazirani na podacima prikupljenim retrospektivnom metodom, sa nalazima o istom predmetu merenja, ali prikupljenim dnevničkim ispitivanjem. Prvo istraživanje ove vrste sproveli su Ptaček i saradnici (Ptacek et al., 1994, prema Stone et al., 1998). Oni su od studenata tražili da sedam dana pre važnog ispita svako veče popune kratak upitnik o tome kako su se tokom tog dana suočavali sa distresom koji su osećali zbog približavajuće stresne situacije, a zatim su pet dana nakon ispita od istih subjekata zahtevali da se prisete misli, osećanja i ponašanja vezanih za evaluativnu situaciju koji su kod njih bili prisutni u proteklom periodu. Korelacije između skorova koji su dobijeni na ova dva različita načina su bile niske do umerene, pa su autori izveli poražavajući zaključak: 
retrospektivni način prikupljanja podataka o suočavanju nije dovoljno pouzdan! Iako je do sada sproveden samo mali broj sličnih istraživanja (Stone et al., 1998; Schwartz et al., 1999, prema Todd et al., 2004), svi dobijeni nalazi potvrđuju Ptačekove rezultate.

\section{SEĆANJE I LIČNOST}

Ljudi su skloni da opažaju, procenjuju, pa i pamte osećanjima obojene stimuluse u skladu sa sopstvenim doživljajem ličnosti i/ili emocionalnim stanjem u kojem se trenutno nalaze. Prema tome, relativno trajne crte ličnosti i prolazna emocionalna stanja mogu da doprinesu distorzijama u sećanjima na osećanja iz prošlosti. Katler i saradnici (Cutler, Larsen, \& Bunce, 1996, prema Levine, \& Safer, 2002) su tražili od ispitanika da procenjuju svoje raspoloženje dva puta dnevno tokom mesec dana. Oni subjekti koji su postigli visoke skorove na upitniku za procenu osobine anksioznosti, ujedno su izveštavali o izraženijim i češćim negativno obojenim svakodnevnim osećanjima, a na kraju istraživanja su izjavljivali da su se tokom trajanja studije osećali čak mnogo gore nego što njihovi prosečni skorovi na svakodnevnim izveštajima sugerišu. Feldman Baret (Feldman Barrett, 1997, prema Safer, Levine, \& Drapalski, 2002) je dobio slične rezultate: osobe sa izraženom crtom neuroticizma sklone su precenjivanju prosečnog intenziteta prethodno zabeleženih neprijatnih emocionalnih stanja. Sejferova i Kojlerova (Safer \& Keuler, 2002) studija o osećanjima kod psihoterapijskih klijenata predstavlja još jedan izvor za donošenje zaključaka o delovanju ličnosti na sećanja na emocije iz prošlosti. Subjekti, koji su u vreme ispitivanja završavali svoj psihoterapijski proces, zamoljeni su da se prisete kvaliteta i jačine emocionalnog distresa koji je kod njih bio prisutan pre započinjanja psihološkog tretmana. Osobe za koje je ustanovljeno da poseduju izražene negativne crte poput neuroticizma i/ili trenutno doživljavaju neprijatna emocionalna stanja, kao što je anksioznost, pokazale su jasnu tendenciju da precenjuju sopstveni pre-terapijski distres. Za razliku od ove grupe ispitanika, subjekti koji su dobijali visoke skorove na merama pozitivnih crta (npr. ego-snaga), potcenjivali su sopstvenu uznemirenost koja je postojala pre započinjanja psihoterapije.

$\mathrm{Na}$ osnovu navedenih nalaza, čini se da sa relativno velikom sigurnošću možemo da tvrdimo da između, s jedne strane, stabilnih ličnih predispozicija $i$ aktuelnih emocionalnih stanja i, s druge strane, memorijskih iskrivljenja, postoji značajna povezanost. Međutim, postavlja se pitanje da li je moguće odrediti koja od ove dve grupe varijabli predstavlja uzroke, a koja posledice. Moguće je da ličnost utiče na memoriju preko delovanja emocija i kognitivnih procena. U ispitivanju sećanja na ispitnu anksioznost iz prošlosti, Sejfer i saradnici (Safer, Levine, \& Drapalski, 2002) su utvrdili da studenti sa dominantnom osobinom neuroticizma su ujedno i subjekti koji izveštavaju o prisustvu najizraženije ispitne anksioznosti pre evaluativne situacije, a što je intenzivnija bila njihova ispitna strepnja, to su pokazivali izraženiju tendenciju ka kasnijem precenjivanju 
evaluativne anksioznosti (činilo im se da su bili više uplašeni, nego što je doista bio slučaj). Prema tome, efekti ličnosti na memorijske distorzije su bili pod medijacijskim uticajem emocionalnih stanja.

Navedeni i drugi slični empirijski podaci sugerišu da je veza između varijabli individualnih razlika i iskrivljenja u sećanju najverovatnije dvosmerna. Tako, na primer, osobe sa izraženom osobinom neuroticizma preteruju u sećanjima na negativna osećanja, dok prilikom prisećanja na pozitivna osećanja pokazuju jasnu sklonost da potcenjuju ta prijatna emocionalna stanja ili čak u potpunosti „zaborave“ da su ih u konkretnoj situaciji doživljavali. S druge strane, isti pojedinci, bazirajući se na generalizacijama o sebi koje potiču iz autobiografskih sećanja, skloni su opisivanju sopstvene ličnosti na taj način da postižu visoke skorove na merama neuroticizma. Prema tome, sećanja na osećanja iz prošlosti potencijalno imaju krucijalnu ulogu u konstrukciji doživljaja ličnog identiteta. Dakle, ličnost oblikuje naša sećanja na prošle emocije, a zauzvrat sećanja na osećanja iz prošlosti učestvuju u „kreiranju“ ličnosti (Levine \& Safer, 2002). 


\section{MEMORY DISTORTIONS IN THE RESEARCH OF EMOTIONS}

Abstract: The memories of one's life, or autobiographical memories, are transitory dynamic mental constructions. The human memory is both solid and fragile. We own durable and lasting traces of many events, but also we can forget other events just moments after they occured. Our memories of past experiences are never exact reproductions of the original, initial events. Besides the memory biases that are related to details about past happenings, distortions are also present in the remembering of emotions that we have experienced during an important past event. The present review paper starts with the scientific definition of the so-called flashbulb memories (emotionally colored memories), and discusses the existing contemporary empirical knowledge about the mistakes and distortions in the process of remembaring past life experiences. A special attention is paid to the number of details that people remember about their autobiographical memories. The study also contains a review of available research results on the accuracy of human memory. The second part of the paper places the phenomenon of memory distortions into the conceptual framework of the Transactional theory of stress, with special attention to the process of remembering coping efforts and mechanisms used in the past. The paper ends with a discussion about the role of neuroticism in the emerging of memory biases.

Key words: memory distortions, emotions, coping, neuroticism. 


\section{LITERATURA}

Breckler, S. J. (1994). Memory for the experience of donating blood: Just how bad was it? Basic and Applied Social Psychology, 15(4), 467-488.

Elofsson, U. O., Scheele, B., Theorell, T., \& Söndergaard, H. P. (2008). Physiological correlates of eye movement desensitization and reprocessing. Journal of Anxiety Disorders, 22(4), 622-634.

Endler, N. S. (1997). Stress, anxiety and coping: The multidimensional interaction model. Canadian Psychology, 38(3), 136-153.

Folkman, S., \& Lazarus, R. S. (1985). If it changes it must be a process: Study of emotion and coping during three stages of a college examination. Journal of Personality and Social Psychology, 48(1), 150-170.

Kensinger, E. A. (2009). Remembering the details: Effects of emotion. Emotion Review, 1(2), 99-113.

Keuler, D. J., \& Safer, M. A. (1998). Memory bias in the assessment and recall of pre-exam anxiety: How anxious was I?. Applied Cognitive Psychology, 12, 127-137.

Levine, L. J. (1997). Reconstructing memory for emotions. Journal of Experimental Psychology: General, 126(2), 165-177.

Levine, L. J., Prohaska, V., Burgess, S. L., Rice, J. A., \& Laulhere, T. M. (2001). Remembering past emotions: The role of current appraisals. Cognition and Emotion, 15(4), 393-417.

Levine, L. J., \& Safer, M. A. (2002). Sources of Bias in Memory for Emotions, Current Directions in Psychological Science, 11, 169-173.

Levine, L. J., \& Bluck, S. (2004). Painting with broad strokes: Happiness and the malleability of event memory. Cognition and Emotion, 18(4), 559-574.

Levine, L. J., \& Pizarro, D. A. (2004). Emotion and memory research: A grumpy overview. Social Cognition, 22(5), 530-554.

Levine, L. J., Whalen, C. K., Henker, B., \& Jamner, L. D. (2005). Looking back on September 11, 2001: Appraised impact and memory for emotions in adolescents and adults. Journal of Adolescent Research, 20(4), 497-523.

Ptacek, J. T., Smith, R. E., Espe, K., \& Raffety, B. (1994). Limited correspondence between daily coping reports and retrospective coping recall. Psychological Assessment, 6, 41-49.

Safer, M. A., Bonnano, G. A., \& Field, N. P. (2001). "It was never that bad": Biased recall of grief and long-term adjustment to the death of a spouse. Memory, 9(3), 195-204.

Safer, M. A., \& Keuler, D. J. (2002). Individual differences in misremembering prepsychotherapy distress: Personality and memory distortion. Emotion, 2(2), 162-178.

Safer, M. A., Levine, L. J., \& Drapalski, A. L. (2002). Distortion in memory for emotions: The contributions of personality and post-event knowledge. Personality and Social Psychology Bulletin, 28(11), 1495-1507.

Safer, M. A., Breslin, C. W., Boesch, R. P., \& Cerqueira, R. (2007). Long-term memory for the emotional gist and the emotional essence of an experience. Memory, 15(8), 861-872.

Smith, R. E., Leffingwell, T. R., \& Ptacek, J. T. (1999). Can people remember how they coped? Factors associated with discordance between same-day and retrospective reports. Journal of Personality and Social Psychology, 76(6), 1050-1061.

Stone, A. A., Schwartz, J. E., Neale, J. M., Shiffman, S., Maro, C. A., Hickcox, M., Paty, J., Porter, L. S., \& Cruise, L. J. (1998). A comparison of coping assessed by ecological 
momentary assessment and retrospective recall. Journal of Personality and Social Psychology, 74(6), 1670-1680.

Todd, M., Tennen, H., Carney, M. A., Armeli, S., \& Affleck, G. (2004). Do we know how we cope? Relating daily coping reports to global and time-limited retrospective assessments, Journal of Personality and Social Psychology, 86(2), 310-319.

Walker, R. W., Vogl, R. J., \& Thompson, C. P. (1997). Autobiographical memory: Unpleasantness fades faster than pleasantness over time. Applied Cognitive Psychology, $11,399-413$.

Walker, R. W., Skowronski, J. J., Gibbons, J. A., \& Vogl, R. J. (2003). On the emotions that accompany autobiographical memories: Dysphoria disrupts tha fading affect bias. Cognition and Emotion, 17(5), 703-723. 